This is a pre-copyedited, author-produced version of an article accepted for publication in European child \& adolescent psychiatry following peer review. The version of record Forte, A., Orri, M., Galéra, C., Pompili, M., Turecki, G., Boivin, M., Tremblay, R. E., and Côté, S. M. Developmental trajectories of childhood symptoms of hyperactivity/inattention and suicidal behavior during adolescence. European child \& adolescent psychiatry , 1-7. 2019.

doi.org/10.1007/s00787-019-01338-0, is available online at: https://doi.org/10.1007/s00787-019-01338-0 


\title{
Developmental trajectories of childhood symptoms of hyperactivity/inattention and suicidal
}

\section{behaviour during adolescence}

Alberto Forte*, $\mathrm{MD}^{1}$, Massimiliano Orri*, $\mathrm{PhD}^{2,3}$, Cédric Galera, $\mathrm{MD}^{4}, \mathrm{PhD}$, Maurizio Pompili, $\mathrm{MD}^{1}, \mathrm{PhD}, \mathrm{Gustavo}$ Turecki, MD, $\mathrm{PhD}^{2}$, Michel Boivin, $\mathrm{PhD}^{5}$, Richard E. Tremblay, $\mathrm{PhD}^{6,7}$, Sylvana M. Côté, $\mathrm{PhD}^{4,8}$.

* These authors contributed equally to this work

Authors' affiliations: 1. Department of Neurosciences, Mental Health and Sensory Organs, Suicide Prevention Center, Sant'Andrea Hospital, Sapienza University of Rome, Rome, Italy; 2. McGill Group for Suicide Studies, Douglas Mental Health University Institute, Department of Psychiatry, McGill University, Montreal, Canada; 3. Bordeaux Population Helth Research Centre, Inserm U1219, Université de Bordeaux, Bordeaux, France; 4. Université de Bordeaux, Department of child and adolescent psychiatry, Centre Hospitalier Perrens, Bordeaux, France; 5. Institute of Genetic, School of Psychology, Laval University, Québec City, Québec, Canada; 6. Departments of Pediatrics and Psychology, University of Montreal, Montreal, Canada; 7. School of Public Health, Physiotherapy and Population Science, University College Dublin, Dublin, Ireland; 8. Department of Social and Preventive Medicine, University of Montreal, Montreal, Québec, Canada;

Corresponding author: Sylvana M Côté. Ste-Justine's Hospital Research Center, 3175, Côte Sainte-Catherine, Étage A, Local A-568, Montréal (Québec) Canada, H3T 1C5. Tel.: 1-514 345-2175, Fax.: 514 345-2176, Email: sylvana.cote.1@umontreal.ca

Word count: 2507

Keywords: Hyperactivity, Inattention, suicidal behaviour, developmental trajectories

\begin{abstract}
Hyperactive/inattentive symptoms (ADHD symptoms) are associated with suicidal behaviour in clinical studies, but there is still a lack of population-based longitudinal investigations on the developmental aspects of this association. Additionally, it is unclear whether the association is similar for boys and girls. The objectives of the study were to test the association between the ADHD symptoms during childhood and suicidal ideation and attempt during adolescence, and to investigate sex differences. 1407 children from the Québec Longitudinal Study of Child Development were followed up from 5 months to 17 years of age. We used teacher-reports of ADHD symptoms from 6 to 12 years, and self-report of suicidal ideation and attempt at 13, 15, and 17 years. We identified 3 ADHD symptoms trajectories: low (boys: $32.2 \%$, girls: 48.7\%), moderate (boys: 44.6\%; girls: 42.2\%) and high (boys: 23.2\%; girls: 9.1\%). Compared to boys on a low trajectory, boys on a moderate trajectory were at higher risk for suicidal ideation $(\mathrm{OR}=4.2,95 \% \mathrm{CI}=1.2$ 14.8), and boys on a high trajectory were at higher risk for suicide attempts (OR: 4.5, 95\%CI: 1.1-17.9). Girls on moderate or high ADHD symptoms trajectories were not at higher risk for suicidal ideation or attempts than girls on low trajectories.

For boys, but not for girls, moderate-to-high ADHD symptoms increased the suicidal risk in adolescence. Interventions with boys showing ADHD symptoms should include a suicide prevention component.
\end{abstract}




\section{Introduction}

Suicidal behavior is most prevalent during adolescence (lifetime prevalence of suicide ideation, plans, and attempts is $12.1 \%, 4.0 \%$, and $4.1 \%$ respectively) [1], and main risk factors for suicide mortality - the second leading cause of death among adolescents [2]. Attention deficit hyperactivity disorder (ADHD), a common disorder affecting 5.3\% of children and adolescents [3], is associated with several adult negative outcomes including suicide mortality, suicide attempt and suicidal ideation (SB) [4]. Despite a few reports, there is still a lack of longitudinal investigations on the association between the course of ADHD symptoms during childhood and SB in adolescents at the population level. Indeed, hyperactive and inattentive symptoms were associated with increased risk for SB in some clinical and population-based samples [5-7]. However only a few longitudinal population-based studies investigated the specific association between hyperactivity/inattention and SB [8-10]. Hurtig et al. conducted a population-based study on a Finnish birth cohort and showed an association between a diagnosis of ADHD and suicidal ideation and deliberate self-harm; however, they took into account only clinically relevant ADHD diagnosis without including developmental traits of hyperactivity and inattention throughout childhood. Sourander and colleagues [8] investigated the association between psychopathology at the age of 8 years and later suicide mortality, but did not focus specifically on the association between the development of hyperactivity/inattention and SB. Finally, Galera et al. found that the association between ADHD and SB held only for males [9], but there seem to be not clear consensus regarding sex differences since another study reported opposite results [10]. Given the importance of individualized preventive intervention taking into account sex differences in adolescent SB [11], it is relevant to clarify the extent to which sex differences play a role in SB of children showing hyperactive/inattentive symptoms. The objective of this study was to clarify the predictive association between childhood symptoms of hyperactivity/impulsivity and inattention (ADHD 
symptoms) and suicidal ideation and attempt in adolescence. Especially, we investigated whether this association is different among girls and boys. We relied on longitudinal data from a population sample from Québec, Canada, using person-centered methods allowing us to identify children with atypically high ADHD symptoms over the course of childhood, and teacher-assessment of children behaviors.

\section{Methods}

\section{Sample}

Participants were drawn from the Quebec Longitudinal Study of Child Development (QLSCD), a representative sample of 2120 infants born in Québec, Canada, in 1997/98 and followed up between 5 months and 17 years. Random selection of the initial representative sample was made through the birth registry and following a procedure based on living area and birth rate. Mothers giving birth after 24 weeks of gestation and speaking French or English were eligible to participate in the study. Data were collected annually or bi-yearly from 1998 through 2015. We used teacher-reports of ADHD symptoms from 6 to 12 years, and self-report of suicidal ideation and attempt from 13 to 17 years. The final sample comprised of $\mathrm{N}=1407$ participants for which data were available on SB (Table 1).

[Table 1 about here]

\section{Ethical Consideration}

Ethical approval was given by the Quebec Statistics Institute and the St-Justine Hospital Research Centre. Written informed consent was obtained from all participants and their parents at each assessment. All adolescents and their parents were provided with a list of resources in case of needing help. 


\section{Measures}

Outcome: Past-Year Suicidal Ideation and Suicide Attempt. Suicidal ideation was assessed at 13, 15, and 17 years using the question: "in the past 12 months, did you ever seriously think of attempting suicide" (yes coded 1, no coded 0; answering "don't know" or refusal was coded as missing). If they answered affirmatively, they were asked: "in the past 12 months, how many times did you attempt suicide", dichotomized as 0 versus $\geq 1$. As in our previous publications $[12,13]$ the following variables were derived: lifetime suicidal ideation (i.e., reporting $\geq 1$ suicide ideation at 13 or 15 or 17 years but never suicide attempt) and lifetime suicide attempt (i.e., reporting $\geq 1$ suicide attempt at 13 or 15 or 17 years).

Exposure: ADHD symptoms during childhood. ADHD symptoms were rated by schoolteachers when participants were $6,7,8,10$, and 12 years of age. Items were derived from the Behavior Questionnaire created for the Canadian National Longitudinal Study of Children and Youth, which incorporates items from the Child Behavior Checklist [14], the Ontario Child Health Study Scales [15], and the Preschool Behavior Questionnaire [16]. The following items were used and summedup to obtain the hyperactivity/inattention score at each year (range: 0 to 18 ; Cronbach's alpha range: 0.74-0.79), for hyperactivity-impulsivity: 1) could not sit still, was restless and hyperactive; 2) was impulsive, acted without thinking; 3) had difficulty waiting for his/her turn in games; 4) couldn't settle down to do anything for more than a few moments; For inattention: 1) was unable to concentrate, could not pay attention for long 2) was easily distracted, had trouble sticking to any activity 3) was inattentive. Each year, a different teacher rated the frequency of these behaviours in the past 6 months $(0=$ never, $1=$ sometimes, $2=$ often $)$. 
Covariates. We used a parsimonious set of covariates for our multiple regression models, all measured before the exposure variable (i.e. age 6 years). Variables were selected on the basis of the literature $[9,17,18]$ and previous studies on the same sample $[12,19,20]$ : maternal depressive symptoms, assessed using a short version of the Centre for Epidemiological Study Depression Scale [21]; children depression-anxiety symptoms, assessed by teachers at age 6 and measured with 5 items ( 3 for anxiety, e.g., "was too fearful or anxious" and 2 for depression, e.g., "seemed to be unhappy or sad;"); family socioeconomic status (SES) at 5 months, an aggregate index of annual gross income, parental education level, and occupational prestige, based on Willms and Shields (range -3=low SES to 3=high SES, centered at zero) and dichotomized into low (i.e, 0-25th percentile) vs non-low (25th-75th percentile). [22]. All questionnaires are available online (http://www.jesuisjeserai.stat.gouv.qc.ca).

\section{Statistical Analyses}

First, we estimated the developmental trajectories of ADHD symptoms among girls and boys, using Group based-trajectory modeling [23]. This approach is based on semiparametric mixture models, and allows us clustering children according to the similarities of their developmental pattern of ADHD symptoms from 6 to 12 years. Both the best number of trajectories and the polynomial order of the trajectories (i.e., intercept only, linear or quadratic; determining the shape of the trajectory) were defined by comparing multiple models on the Bayesian Information Criterion [23].

Second, we used binary logistic regressions to test the predictive association between trajectory membership and suicidal ideation and attempt. We estimated unadjusted models as well as models adjusted for the influence of the selected covariates. Missing data on these covariates were handled using multiple imputations by chained equation: the models were estimated on 50 complete 
datasets, and the results were pooled. Data analysis was performed using Stata version 14, and the trajectories were estimated using the traj procedure.

\section{Results}

Prevalence of suicidal ideation and suicide attempt

At 13, 15, and 17 years respectively, 23 (1.9\%), 43 (3.3\%), and 51 (4.3\%) adolescents reported suicidal ideation in the past year, while at those same ages respectively $28(2.4 \%), 37(2.8 \%)$, and $28(2.4 \%)$ adolescents reported suicide attempt in the past year. In total, 29 boys (4.3\%) and 60 girls (8.1\%) reported suicidal ideation at least at one assessment (i.e, lifetime suicidal ideation), while 19 boys (2.8\%) and 61 girls $(8.2 \%)$ reported suicide attempt at least at 1 assessment (i.e., lifetime suicide attempt; Table 2).

[Table 2 about here]

\section{Developmental trajectories of ADHD symptoms}

For both boys and girls, we identified a 3-group model as having the best fit (Figure 1): low trajectory (boys: $32.2 \%$, girls: $48.7 \%$ ), moderate trajectory (boys: $44.6 \%$; girls: $42.2 \%$ ), high trajectory (boys: 23.2\%; girls: 9.1\%). The trajectories showed similar developmental patterns for boys and girls. However, boys on the high trajectory had higher ADHD symptoms scores than girls on the high trajectory. Additionally, the proportion of children within each trajectory was different, with the high trajectory being larger for boys than for girls, and the low trajectory being larger for girls than for boys.

[Figure 1 about here] 
Prevalence of suicidal ideation and attempt in each trajectory are shown in Table 2. For girls, the highest prevalence of suicidal ideation was found in the high trajectory $(11.1 \%)$, while girls in the moderate and low trajectories had a slightly lower suicide ideation rate $(7.3 \%$ and $8.1 \%$, respectively). Logistic regression analyses (Table 3) showed that, girls in the low, moderate, and high trajectories were at similar risk of suicidal ideation (moderate vs low, $\mathrm{OR}=0.9,95 \% \mathrm{CI}=0.5$ 1.5; high vs low, $\mathrm{OR}=1.4,95 \% \mathrm{CI}=0.6-3.3)$, even after adjustment for the selected covariates (moderate vs low, $\mathrm{OR}=1.0,95 \% \mathrm{CI}=0.5-1.7$; high vs low, $\mathrm{OR}=1.8,95 \% \mathrm{CI}=0.7-5.0$ ).

Boys in the high and moderate trajectories had a similar suicidal ideation rate $(5.3 \%$ and $5.9 \%$, respectively), which was higher than that of boys in the low trajectory (1.4\%). Consistently, logistic regression analysis showed that boys in the moderate and high trajectories had a 4-fold increased risk of suicide ideation compared to boys in the low trajectory (moderate, OR: 4.4, 95\%CI: 1.3-15.1; high, $\mathrm{OR}=3.9,95 \% \mathrm{CI}=1.0-14.9)$. Odds ratios remained similar after adjustment for the selected covariables, although below the significance threshold for the high trajectory (moderate, OR: 4.2, 95\%CI: 1.2-14.8; high, $\mathrm{OR}=3.6,95 \% \mathrm{CI}=0.8-15.1$ ).

\section{Association between ADHD symptoms trajectories and suicide attempt}

There was a dose-response pattern indicating that the higher the ADHD symptoms, the higher the rate of suicide attempts (girls: $5.1 \%, 9.9 \%, 17,4 \%$; boys: $1.9 \%, 2.6 \%, 4.6 \%$, respectively for the low, moderate, and high trajectories; Table 2). Logistic regression (Table 3) showed that girls in both high $(\mathrm{OR}=3.9,95 \% \mathrm{CI}=1.7-8.6)$ and moderate trajectory $(\mathrm{OR}=2.0,95 \% \mathrm{CI}=1.1-3.6)$ had a higher crude risk for attempting suicide compared to girls in the low trajectory. However, those risks decreased and became non-significant after adjustment for the covariates (moderate, $\mathrm{OR}=1.6$, $95 \% \mathrm{CI}=0.8-3.0 ;$ high, $\mathrm{OR}=2.3,95 \% \mathrm{CI}=0.9-5.8)$. 
A different pattern was observed for boys. Compared to boys in the low trajectory, boys in the moderate and high trajectories had, respectively, 1.4-fold $(\mathrm{OR}=1.4,95 \% \mathrm{CI}=0.4-4.7)$ and 2.5fold $(\mathrm{OR}=2.5,95 \% \mathrm{CI}=0.7-8.7)$ increased risk for suicide attempt. After accounting for the confounding role of the covariates, the risk became statistically significant for the boys in the high trajectory (OR: 4.5, 95\%CI: 1.1-17.9), but not for the boys in the moderate trajectory $(\mathrm{OR}=1.8$, $95 \% \mathrm{CI}=0.5-6.3)$.

\section{[Table 3 about here]}

\section{Discussion}

The objectives of this population-based study were to test the predictive association between childhood ADHD symptoms and suicide ideation and attempts in adolescence, and to test whether the suicidal risk differed by sex. Our analyses showed that moderate to high levels of ADHD symptoms did not convey the same suicidal risk for boys and girls. We found that boys following moderate and high ADHD symptoms trajectories during the course of childhood (6-12 years) had a higher risk of suicidal ideation in adolescence (13-17 years), compared to boys following a low ADHD symptoms trajectory. In contrast, girls following a moderate or high ADHD symptoms trajectory did not have a heightened risk for suicidal ideation, compared to girls following a low ADHD symptoms trajectory. These associations were of similar magnitude after taking into account the confounding effects of childhood depressive symptoms, socioeconomic status, and maternal depression.

For suicide attempts, only boys following a high ADHD symptoms trajectory showed an increased (4.5 times higher) risk of suicide attempt compared to boys following a low trajectory. The risk of suicide attempts was not higher for girls on the high ADHD symptoms trajectory compared to girls on the low trajectory.

Our results are consistent with previous studies suggesting that ADHD symptoms might be considered early risk factors for suicide attempts during adolescence, especially among boys.[8, 9] 
Our findings also extend prior knowledge in several ways. First, to our knowledge, this is the first population-based study to investigate the association between ADHD symptoms and SB using group-based trajectory modeling [23]. Given the developmental origins of suicidal behaviour, it is important to identify the developmental aspects of ADHD symptoms and its longitudinal association with suicidal behaviour using statistical techniques that account for population heterogeneity in the long term development of ADHD symptoms [7-9]. Specifically, such techniques rely on a data driven approach that allows one to identify homogeneous group of children with typical and atypically high levels of symptoms without using arbitrary classifications. Second, previous studies were mainly based on cross-sectional designs and focused on clinical populations $[6,7,10]$. Third, as previous studies mainly documented the association between ADHD symptoms and suicide mortality or serious attempts (i.e., requiring hospitalization) [8] in boys, our findings extend previous reports by showing that the association also holds for selfreported suicidal ideation and self-reported attempt. This is important because suicidal ideation precede suicide attempt in most cases. Only one previous population-based study found a positive association between childhood ADHD symptoms and SB among boys, although it was not based on a birth cohort $[8,9]$.

The underlying mechanisms of the sex difference in the association between ADHD symptoms and SB are still unclear, but they might be related to the type of ADHD symptoms that boys and girls experience. Boys with ADHD are more likely than girls with ADHD to display hyperactive-impulsive symptoms and less likely to experience inattentive symptoms [24]. Previous studies indicated that impulsivity is one of the pathway to suicidal behaviors, both in boys and girls [25-27], and a recent study also highlighted that different domains of impulsivity are connected to suicidal ideation and suicide attempt (respectively Pervasive Influence of Feelings and Feelings Trigger Action) [28]. Thus boys' higher levels of ADHD symptoms may explain why the association between hyperactivity-inattention and suicidal outcomes holds mainly for boys [28, 29]. 
Moreover, the same level of suicidal ideation may convert more easily into the acting out of suicide attempts in boys than in girls being facilitated by higher levels of hyperactivity-impulsivity, as previously suggested [12,30-32]. Previous studies distinguishing the role of impulsivity and inattention show that those symptoms have different long term effect on educational and mental health outcome $[33,34]$ but to our knowledge no study investigated suicidal outcomes. Therefore, studies distinguishing the role of inattention from that of hyperactive/impulsive symptoms in boys and girls are needed to clarify the origin of the sex difference that we observed. The lack of risk awareness which can be part of ADHD itself might also explain the finding that ADHD symptoms are risk factors for suicide attempt and ideation among boys [4, 9], as these symptoms may confer to adolescents a higher risk of acting without considering the consequences of their acts. However, further studies are needed to clarify the underlying mechanisms of this association.

Our findings have clear clinical and preventive implications: boys presenting with moderate or high levels of ADHD symptoms throughout elementary school, might be considered more at risk for suicidal ideation and attempt later in life. These findings may guide clinicians to a more focused detection and prevention of SB in adolescents who manifested these symptoms throughout elementary school.

To our knowledge this is the first population-based study using trajectory modelling to clarify the association between ADHD symptoms during childhood and suicidal behaviour during adolescence, with a focus on sex differences. Strengths of the study include: the use of a population-based sample followed-up from birth to 17 years; the yearly or bi-yearly assessments of hyperactivity/impulsivity and inattention by 5 different teachers providing independent assessments by adults with a good sense of normative behaviours in a group context [35], and the assessment of suicidality at 3 time points during adolescence.

However, caution in interpreting the results is warranted in light of the following limitations. First, attrition (eg, emigration, loss to follow-up, and refusal) is a limitation of all longitudinal 
cohort studies including this one. To limit the loss of data, we used multiple imputations to deal with missing on the covariates. Moreover, as the participants with the more severe mental health symptoms tended to drop out, our models are likely to provide conservative estimate of the association between ADHD symptoms and suicidality in the population. Second, we focused on symptoms of hyperactivity/impulsivity and inattention, as the prevalence of ADHD diagnoses is low in population-based samples and we did not obtain clinical mental health evaluation during childhood.

This population-based study showed that boys with high and moderate levels of ADHD symptoms during childhood are at higher risk for later suicidal behaviour. In particular, boys with moderate and high level of ADHD symptoms exhibited a higher risk for suicidal ideation, and a 4.5 times higher risk of suicide attempts in adolescence compared to those with low levels of ADHD symptoms. Interventions with pre-adolescent and adolescent boys showing ADHD symptoms should include a suicide prevention component. Population level suicide prevention for adolescents should particularly target boys with a history of ADHD problems.

\section{References}

1. Nock MK, Green JG, Hwang I, et al (2013) Prevalence, correlates, and treatment of lifetime suicidal behavior among adolescents: results from the National Comorbidity Survey Replication Adolescent Supplement. JAMA psychiatry 70:300-10. doi: 10.1001/2013.jamapsychiatry.55

2. Sullivan EM, Annest JL, Simon TR, et al (2015) Suicide trends among persons aged 10-24 years--United States, 1994-2012. MMWR Morb Mortal Wkly Rep 64:201-5.

3. Polanczyk G, de Lima MS, Horta BL, et al (2007) The worldwide prevalence of ADHD: a systematic review and metaregression analysis. Am J Psychiatry 164:942-948. doi: 164/6/942 [pii]\r10.1176/ajp.2007.164.6.942 
4. Impey M, Heun R (2012) Completed suicide, ideation and attempt in attention deficit hyperactivity disorder. Acta Psychiatr Scand 125:93-102. doi: 10.1111/j.16000447.2011.01798.x

5. Balazs J, Miklósi M, Keresztény Á, et al (2014) Attention-deficit hyperactivity disorder and suicidality in a treatment naïve sample of children and adolescents. J Affect Disord 152154:282-287. doi: 10.1016/j.jad.2013.09.026

6. Ljung T, Chen Q, Lichtenstein P, Larsson H (2014) Common etiological factors of attentiondeficit/hyperactivity disorder and suicidal behavior: a population-based study in Sweden. JAMA psychiatry 71:958-64. doi: 10.1001/jamapsychiatry.2014.363

7. Chronis-Tuscano A, Molina BSG, Pelham WE, et al (2010) Very early predictors of adolescent depression and suicide attempts in children with attention-deficit/hyperactivity disorder. Arch Gen Psychiatry 67:1044-51. doi: 10.1001/archgenpsychiatry.2010.127

8. Sourander A, Klomek AB, Niemelä S, et al (2009) Childhood predictors of completed and severe suicide attempts: findings from the Finnish 1981 Birth Cohort Study. Arch Gen Psychiatry 66:398-406. doi: 10.1001/archgenpsychiatry.2009.21

9. Galéra C, Bouvard MP, Encrenaz G, et al (2008) Hyperactivity-inattention symptoms in childhood and suicidal behaviors in adolescence: the Youth Gazel Cohort. Acta Psychiatr Scand 118:480-9. doi: 10.1111/j.1600-0447.2008.01262.x

10. Hurtig T, Taanila A, Moilanen I, et al (2012) Suicidal and self-harm behaviour associated with adolescent attention deficit hyperactivity disorder-a study in the Northern Finland Birth Cohort 1986. Nord J Psychiatry 66:320-8. doi: 10.3109/08039488.2011.644806

11. Bennett K, Rhodes AE, Duda S, et al (2015) A Youth Suicide Prevention Plan for Canada: A Systematic Review of Reviews. Can J Psychiatry 60:245-257. doi: $10.1177 / 070674371506000603$

12. Orri M, Galera C, Turecki G, et al (2018) Association of Childhood Irritability and 
Depressive/Anxious Mood Profiles With Adolescent Suicidal Ideation and Attempts. JAMA Psychiatry 75:465. doi: 10.1001/jamapsychiatry.2018.0174

13. Orri M, Galera C, Turecki G, et al (2019) Pathways of Association Between Childhood Irritability and Adolescent Suicidality. J Am Acad Child Adolesc Psychiatry 58:99-107.e3. doi: 10.1016/j.jaac.2018.06.034

14. Achenbach TM, Rescorla LA (2001) Manual for ASEBA School Age Forms \& Profiles. University of Vermont Research Center for Children, Youth and Families, Burlington, VT

15. Boyle MH, Offord DR, Racine Y, et al (1993) Evaluation of the original Ontario Child Health Study scales. Can J Psychiatry 38:397-405. doi: 10.1177/070674379303800605

16. Tremblay RE, Desmarais-Gervais L, Gagnon C, Charlebois P (1987) The Preschool Behaviour Questionnaire: Stability of its Factor Structure Between Cultures, Sexes, Ages and Socioeconomic Classes. Int J Behav Dev 10:467-484. doi: 10.1177/016502548701000406

17. Hammerton G, Zammit S, Mahedy L, et al (2015) Pathways to suicide-related behavior in offspring of mothers with depression: the role of offspring psychopathology. J Am Acad Child Adolesc Psychiatry 54:385-93. doi: 10.1016/j.jaac.2015.02.006

18. Galera C, Pingault J-B, Michel G, et al (2014) Clinical and social factors associated with attention-deficit hyperactivity disorder medication use: population-based longitudinal study. Br J Psychiatry 205:291-297. doi: 10.1192/bjp.bp.113.141952

19. Galéra C, Côté SM, Bouvard MP, et al (2011) Early Risk Factors for HyperactivityImpulsivity and Inattention Trajectories From Age 17 Months to 8 Years. Arch Gen Psychiatry 68:1267. doi: 10.1001/archgenpsychiatry.2011.138

20. Salla J, Michel G, Pingault JB, et al (2016) Childhood trajectories of inattentionhyperactivity and academic achievement at 12 years. Eur Child Adolesc Psychiatry 25:11951206. doi: 10.1007/s00787-016-0843-4

21. Poulin C, Hand D, Boudreau B (2005) Validity of a 12-item version of the CES-D used in 
the National Longitudinal Study of Children and Youth. Chronic Dis Can 26:65-72.

22. Willms D, Shields M (1996) A measure of socioeconomic status for the National Longitudinal Study of Childrenitle. Center for Policy Research in Education, University of New Brunswick and Statistics Canada, Fredericton, NB

23. Nagin DS (2005) Group-Based Modeling of Development. Harvard University Press, Cambridge, Mass

24. Nussbaum NL (2012) ADHD and Female Specific Concerns. J Atten Disord 16:87-100. doi: $10.1177 / 1087054711416909$

25. Conner KR, Duberstein PR, Conwell Y, et al (2001) Psychological vulnerability to completed suicide: a review of empirical studies. Suicide Life Threat Behav 31:367-85.

26. Swann AC, Dougherty DM, Pazzaglia PJ, et al (2005) Increased impulsivity associated with severity of suicide attempt history in patients with bipolar disorder. Am J Psychiatry 162:1680-7. doi: 10.1176/appi.ajp.162.9.1680

27. Stewart JG, Kim JC, Esposito EC, et al (2015) Predicting suicide attempts in depressed adolescents: Clarifying the role of disinhibition and childhood sexual abuse. J Affect Disord 187:27-34. doi: 10.1016/j.jad.2015.08.034

28. Auerbach RP, Stewart JG, Johnson SL (2017) Impulsivity and Suicidality in Adolescent Inpatients. J Abnorm Child Psychol 45:91-103. doi: 10.1007/s10802-016-0146-8

29. Alasaarela L, Hakko H, Riala K, Riipinen P (2017) Association of Self-reported Impulsivity to Nonsuicidal Self-Injury, Suicidality, and Mortality in Adolescent Psychiatric Inpatients. J Nerv Ment Dis 205:340-345. doi: 10.1097/NMD.0000000000000655

30. Huang Y-H, Liu H-C, Tsai F-J, et al (2017) Correlation of impulsivity with self-harm and suicidal attempt: a community study of adolescents in Taiwan. BMJ Open 7:e017949. doi: 10.1136/bmjopen-2017-017949

31. Wang L, He CZ, Yu YM, et al (2014) Associations between impulsivity, aggression, and 
suicide in Chinese college students. BMC Public Health 14:551. doi: 10.1186/1471-2458-14551

32. Orri M, Perret LC, Turecki G, Geoffroy M-C (2018) Association between irritability and suicide-related outcomes across the life-course. Systematic review of both community and clinical studies. J Affect Disord 239:220-233. doi: 10.1016/j.jad.2018.07.010

33. Salla J, Michel G, Pingault JB, et al (2016) Childhood trajectories of inattentionhyperactivity and academic achievement at 12 years. Eur Child Adolesc Psychiatry 25:11951206. doi: 10.1007/s00787-016-0843-4

34. Pingault J-B, Tremblay RE, Vitaro F, et al (2011) Childhood Trajectories of Inattention and Hyperactivity and Prediction of Educational Attainment in Early Adulthood: A 16-Year Longitudinal Population-Based Study. Am J Psychiatry 168:1164-1170. doi: 10.1176/appi.ajp.2011.10121732

35. Tripp G, Schaughency EA, Clarke B (2006) Parent and teacher rating scales in the evaluation of attention-deficit hyperactivity disorder: contribution to diagnosis and differential diagnosis in clinically referred children. J Dev Behav Pediatr 27:209-18. 
Table 1. Socio-demographic characteristics of the sample

\begin{tabular}{|c|c|c|c|c|}
\hline & $\begin{array}{c}\text { Attempt } \\
(\mathrm{N}=80)\end{array}$ & $\begin{array}{c}\text { Ideation } \\
(\mathrm{N}=89)\end{array}$ & $\begin{array}{c}\text { No attempt/ideation } \\
(\mathrm{N}=1238)\end{array}$ & $p$-value \\
\hline \multicolumn{5}{|l|}{ Child characteristics } \\
\hline Sex male, $\mathrm{N}(\%)$ & $19(23.7)$ & $29(32.6)$ & $617(49.8)$ & 0.000 \\
\hline Depressive/anxiety symptoms & $2.4(1.4)$ & $2.1(1.6)$ & $2.1(1.6)$ & 0.255 \\
\hline ADHD medication use, $\mathrm{N}(\%)$ & $15(18.7)$ & $14(15.7)$ & $152(12.2)$ & 0.121 \\
\hline Opposition & $3.8(1.5)$ & $3.5(1.5)$ & $3.6(1.5)$ & 0.363 \\
\hline Low birth weight $(<2500 \mathrm{~g}), \mathrm{N}(\%)$ & $3(3.7)$ & $1(1.1)$ & $40(3.2)$ & 0.515 \\
\hline \multicolumn{5}{|l|}{ Parents and family characteristics } \\
\hline Low Socioeconomic Status, N (\%) & $28(35.9)$ & $21(23.6)$ & $265(21.5)$ & 0.013 \\
\hline Maternal age at child birth & $28.5(5.5)$ & $30.0(5.3)$ & $29.3(5.1)$ & 0.191 \\
\hline Paternal age at child birth & $31.6(5.5)$ & $32.9(4.7)$ & $32.2(5.5)$ & 0.315 \\
\hline Family dysfunction & $2.0(1.5)$ & $1.7(1.4)$ & $1.7(1.4)$ & 0.115 \\
\hline Family structure non-intact, N (\%) & $22(37.5)$ & $13(14.6)$ & $215(17.4)$ & 0.053 \\
\hline Smoking during pregnancy, $\mathrm{N}(\%)$ & $24(30.7)$ & $18(20.2)$ & $299(24.2)$ & 0.276 \\
\hline \multicolumn{5}{|l|}{ Parental mental health } \\
\hline Maternal suicide attempt, N (\%) & $3(3.8)$ & $2(2.2)$ & $19(1.5)$ & 0.387 \\
\hline Maternal depression & $1.6(1.1)$ & $1.4(1.1)$ & $1.4(1.1)$ & 0.207 \\
\hline
\end{tabular}

The table provides basic socio-demographic characteristics of the sample. Descriptive statistics are mean (standard deviations) if not otherwise indicated. P-values are based on ANOVA (continuous variables) or Chi-squares (categorical variables).

Data were compiled from the final master file of the Québec Longitudinal Study of Child Development (1998-2015), Québec Government, Québec Statistic Institute. 
Table 2. Prevalence of suicidal ideation and attempt by trajectory and sex

\begin{tabular}{|c|c|c|c|c|c|c|c|c|}
\hline & \multirow{2}{*}{\multicolumn{2}{|c|}{$\begin{array}{l}\text { Suicidal behavior Entire } \\
\text { sample }\end{array}$}} & \multicolumn{6}{|c|}{ Suicidal behavior by trajectory } \\
\hline & & & \multicolumn{2}{|c|}{ Low trajectory } & \multicolumn{2}{|c|}{ Moderate trajectory } & \multicolumn{2}{|c|}{ High trajectory } \\
\hline & $\begin{array}{c}\text { Boys } \\
n=665\end{array}$ & $\begin{array}{c}\text { Girls } \\
\mathrm{n}=742\end{array}$ & $\begin{array}{c}\text { Boys } \\
n=211\end{array}$ & $\begin{array}{c}\text { Girls } \\
\mathrm{n}=367\end{array}$ & $\begin{array}{c}\text { Boys } \\
\mathrm{n}=303\end{array}$ & $\begin{array}{c}\text { Girls } \\
=312 \\
\end{array}$ & $\begin{array}{c}\text { Boys } \\
n=151\end{array}$ & $\begin{array}{c}\text { Girls } \\
\mathrm{n}=63\end{array}$ \\
\hline Ideation & $29(4.3)$ & $60(8.1)$ & $3(1.4)$ & $30(8.1)$ & $18(5.9)$ & $23(7.3)$ & $8(5.3)$ & $7(11.1)$ \\
\hline Attempt & $19(2.8)$ & $61(8.2)$ & $4(1.9)$ & $19(5.1)$ & $8(2.6)$ & $31(9.9)$ & $7(4.6)$ & 11(17.4) \\
\hline
\end{tabular}

The table provides count $(\mathrm{N})$ and percentage $(\%)$ of adolescents reporting suicide ideation and attempt at 13-17 years for each trajectory and by sex. 
Table 3. Logistic regression models predicting suicidal ideation and suicide attempt at 13-17 years

\begin{tabular}{|c|c|c|c|c|}
\hline \multirow[b]{2}{*}{$\begin{array}{l}\text { ADHD symptoms } \\
\text { trajectory }\end{array}$} & \multicolumn{2}{|c|}{ Suicidal ideation } & \multicolumn{2}{|c|}{ Suicide attempt } \\
\hline & $\begin{array}{c}\text { Unadjusted } \\
\text { OR }(95 \% \mathrm{CI}) \\
\end{array}$ & $\begin{array}{c}\text { Adjusted } \\
\text { OR }(95 \% \mathrm{CI})^{\mathrm{a}} \\
\end{array}$ & $\begin{array}{c}\text { Unadjusted } \\
\text { OR }(95 \% \mathrm{CI}) \\
\end{array}$ & $\begin{array}{c}\text { Adjusted } \\
\text { OR }(95 \% \mathrm{CI})^{\mathrm{a}} \\
\end{array}$ \\
\hline \multicolumn{5}{|l|}{ Boys (665) } \\
\hline Low ADHD symptoms & 1 [reference] & 1 [reference] & 1 [reference] & 1 [reference] \\
\hline $\begin{array}{l}\text { Moderate ADHD } \\
\text { symptoms }\end{array}$ & $4.4(1.3-15.1)$ & $4.2(1.2-14.8)$ & $1.4(0.4-4.7)$ & $1.8(0.5-6.3)$ \\
\hline High ADHD symptoms & $3.9(1.0-14.9)$ & $3.6(0.8-15.1)$ & $2.5(0.7-8.7)$ & $4.5(1.1-17.9)$ \\
\hline \multicolumn{5}{|l|}{ Girls (742) } \\
\hline Low ADHD symptoms & 1 [reference] & 1 [reference] & 1 [reference] & 1 [reference] \\
\hline $\begin{array}{l}\text { Moderate ADHD } \\
\text { symptoms }\end{array}$ & $0.9(0.5-1.5)$ & $1.0(0.5-1.7)$ & $2.0(1.1-3.6)$ & $1.6(0.8-3.0)$ \\
\hline High ADHD symptoms & $1.4(0.6-3.3)$ & $1.8(0.7-5.0)$ & $3.9(1.7-8.6)$ & $2.3(0.9-5.8)$ \\
\hline
\end{tabular}

${ }^{a}$ Odds ratios adjusted for child depressive symptoms, socioeconomic status, and maternal depression 
Figure 1. Trajectories of ADHD symptoms among boys and girls
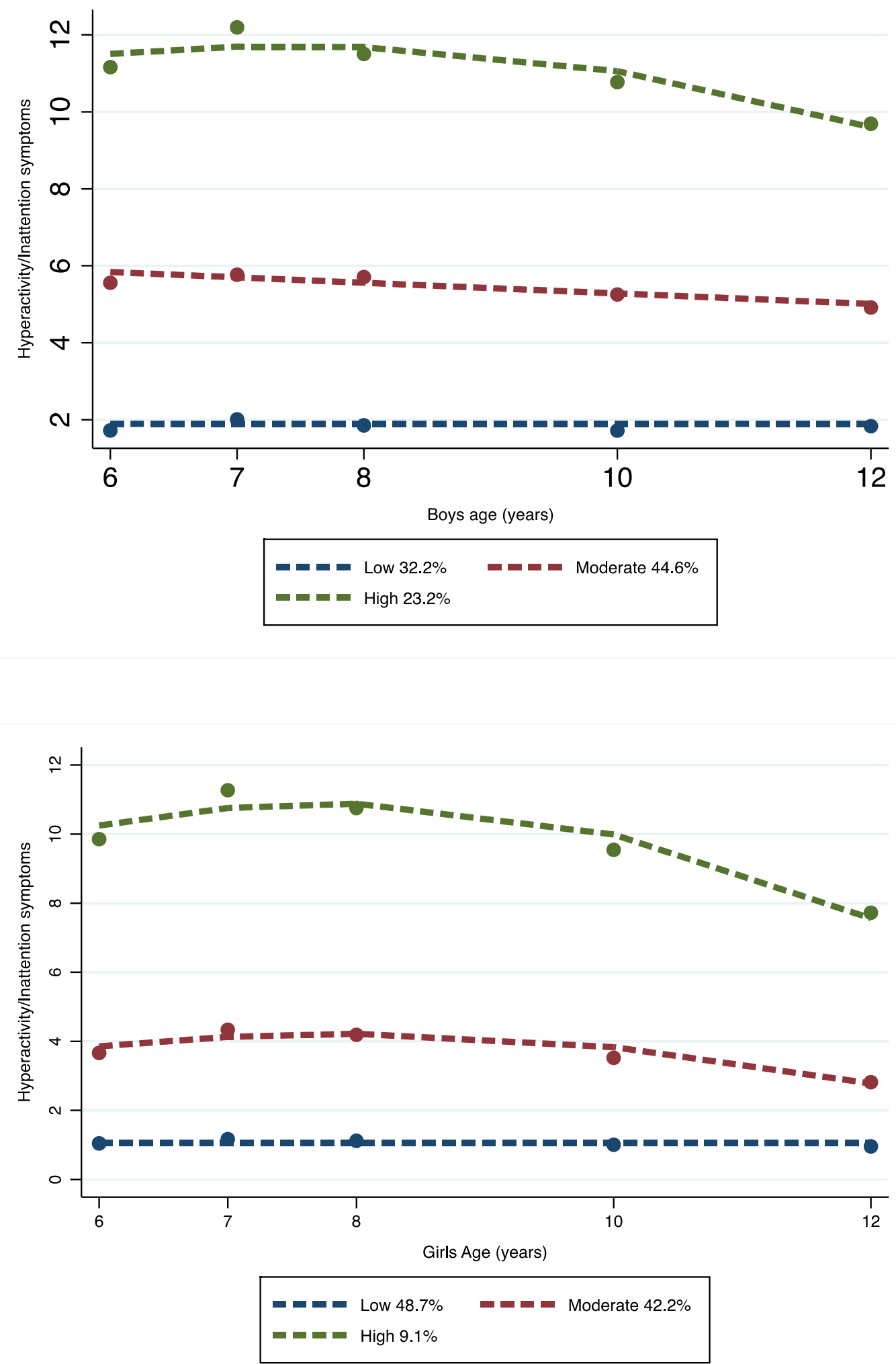